\title{
GLOBALIZAÇÃO E CAFÉS ESPECIAIS: A PRODUÇÃO DO COMÉRCIO JUSTO DA ASSOCIAÇÃO DOS AGRICULTORES FAMILIARES DO CÓRREGO D'ANTAS - ASSODANTAS, POÇOS DE CALDAS (MG)
}

\author{
Globalization and specialty coffees: the Fair trade production of Associação dos Agricultores \\ Familiares do Córrego D’Antas - ASSODANTAS, Poços de Caldas (MG)
}

Samuel Frederico

Universidade Estadual Paulista, Rio Claro, São Paulo, Brasil sfrederico@rc.unesp.br

Marcela Barone

Universidade Estadual Paulista, Rio Claro, São Paulo, Brasil baronemarcela@yahoo.com.br

Artigo recebido em 12/01/2015 e aceito para publicação em 19/11/2015

RESUMO: Desde a última grande crise internacional do café, na década de 1990, a produção de cafés especiais tem sido considerada uma das principais alternativas de mercado para os pequenos cafeicultores. Todavia, o aumento do consumo mundial deste tipo de café atraiu também a atenção de grandes empresas exportadoras, torrefadoras e varejistas, com consequente padronização da produção. Se por um lado a entrada neste tipo de mercado trouxe importantes benefícios para pequenos produtores, particularmente, em países reconhecidos pela produção de cafés de qualidade inferior e pela insuficiente organização coletiva dos cafeicultores, como o caso brasileiro, por outro, a regulação externa e a atuação de grandes empresas têm alargado as diferenças de poder e distribuição do valor ao longo do circuito espacial produtivo. Dessa forma, este artigo tem como objetivo principal analisar a inserção dos pequenos produtores da Associação dos Agricultores Familiares do Córrego D’Antas, Poços de Caldas (MG), no Comércio Justo. Para isso, parte-se do debate sobre a mundialização e padronização da produção de cafés especiais. Em seguida, aprofunda-se a análise no Comércio Justo, para, finalmente, destacar os benefícios e desafios enfrentados pela Assodantas.

Palavras-chaves: Globalização; Cafeicultura; Cafés especiais; Comércio Justo; Assodantas - Poços de Caldas-MG (Brasil).

ABSTRACT: Since the last major international coffee crisis, in the 1990s, the production of specialty coffee has been considered one of the main market alternatives for small farmers. However, the increase in world consumption of this type of coffee has also attracted the attention of major exporters, roasters and retailers, with consequent standardization of production. On the one hand, the entry in such markets has important benefits for small producers, particularly in countries recognized by the production of lower quality coffee and insufficient collective organization of farmers, as the Brazilian case, on the other hand, external regulation and the role of large companies have extended the differences of power and distribution of value along the productive spacial circuit. Therefore, this article aim to examine the paradox resulting from the 
insertion of small producers of the Associação dos Agricultores familiares do Córrego D'Antas, Poços de Caldas (MG), in the Fairtrade market. For this, starts the debate on globalization and standardization of specialty coffee production. Then deepens the analysis in Fairtrade and finally, it highlight the benefits and challenges faced by Assodantas.

Keywords: Globalization; Coffee production; Specialty coffee; Fair Trade; Assodantas - Poços de Caldas; Minas Gerais (Brazil).

\section{INTRODUÇ̃̃O}

A produção de cafés especiais é um dos temas mais discutidos e polêmicos na cafeicultura mundial. Considerada por alguns, como uma das poucas saídas para a permanência na atividade dos pequenos produtores (SOUZA, 2006), e por outros, como mais um nicho de mercado produzido e apropriado pelas grandes empresas globais (tradings, torrefadoras e cafeterias) (DAVIRON; VAGNERON, 2010), os cafés especiais já representam $12 \%$ do mercado internacional da bebida (BSCA, 2013).

Dentre os principais tipos de cafés especiais produzidos no território brasileiro (Orgânico, Gourmet, Comércio Justo e com Indicação Geográfica), este artigo se propõe a debater o paradoxo advindo da inserção de pequenos produtores no Comércio Justo (CJ). Se por um lado, a entrada neste tipo de mercado traz importantes benefícios para pequenos produtores, particularmente, em países reconhecidos pela produção de cafés de qualidade inferior e pela insuficiente organização coletiva dos cafeicultores, como o caso brasileiro, por outro, a regulação externa e a atuação de grandes empresas têm alargado as diferenças de poder e distribuição do valor entre produtores, certificadores e corporações mundiais.

O Comércio Justo surgiu na década de 1960, comointuito depropiciarumamaiorinter-relaçãoentre pequenos produtores dos países subdesenvolvidos e consumidores da Europa e EUA (JAFFEE, 2012). Inicialmente baseado em redes informais, o Comércio Justo tinha como objetivo principal se opor à lógica das commodities (FREDERICO, 2013), isto é, garantir maior transparência nas negociações, estabelecer parcerias comerciais de longo prazo e assegurar a identidade dos produtores. No entanto, como descrito de forma mais detalhada ao longo deste artigo, a criação de padrões comuns e a certificação de terceiros, com a forte expansão do CJ na década de 1990, resultaram na diminuição da transparência e na fácil permutabilidade dos produtores. Tratase, como asseveram Daviron e Vagneron (2011), de uma recommoditização das formas alternativas de comércio criadas nas décadas de 1960 e 70, pela reintrodução da concorrência entre produtores no mercado mundial.

Todavia, apesar da contradição em tentar resolver as desigualdades do comércio internacional por meio do próprio mercado, é inegável os benefícios do Comércio Justo para algumas associações brasileiras de produtores. Mesmo que os pequenos cafeicultores continuem subordinados à lógica do mercado internacional de commodities, a inserção no Comércio Justo propicia: maior organização coletiva; melhoria dos padrões produtivos e da qualidade do café; diminuição do número de intermediários; maior transparência nas negociações e elevação da renda.

Para discutir as contradições e a inserção de pequenos cafeicultores no Comércio Justo, este artigo está organizado em três partes, além desta breve introdução e as considerações finais. A primeira parte trata da "crise do café" a partir da década de 1990, com a maior regulação corporativa, e a consequente expansão da produção de cafés especiais, como uma alternativa dos pequenos produtores à redução dos preços internacionais. Em seguida, aborda-se o surgimento do Comércio Justo, na década de 1960, e sua expansão e formalização na última década do século XX, com destaque para a participação da cafeicultura. Por fim, discute-se a experiência da inserção da Associação dos Agricultores Familiares do Córrego D’Antas (Assodantas), localizada no município de Poços de Caldas (MG), no circuito espacial produtivo do Comércio Justo. 


\section{COMMODITIZAÇÃO E CAFÉS ESPECIAIS}

O café é a commodity agrícola mais comercializada no mundo e a segunda maior em valor de mercado, atrás somente do petróleo (TALBOT, 2004). O seu circuito espacial produtivo (SANTOS, 1986; CASTILLO; FREDERICO, 2004), isto é, a circulação de bens e produtos entre as diferentes etapas produtivas, conecta milhares de produtores em dezenas de países, a milhões de consumidores dispersos pelo mundo. O cafeeiro da espécie Arábica possui importantes limitantes edafoclimáticos (altitudes entre 800 e $2.500 \mathrm{~m}$ e temperaturas médias entre 18 e $25^{\circ} \mathrm{C}$ ), o que restringe a sua produção a algumas regiões de países tropicais. Todavia, a maior parte do seu consumo se realiza nos países temperados como os EUA, Japão e Europa Ocidental (com exceção do Brasil, segundo maior consumidor mundial).

Entre a colheita, em países como Brasil, Colômbia e Vietnã (responsáveis por cerca de 60\% das exportações mundiais), e o consumo final, o café precisa ser beneficiado, comercializado, armazenado, transportado, torrado e moído. A regulação dos fluxos ao longo das etapas produtivas envolve agentes com diferentes objetivos, estratégias e escalas de atuação: desde pequenos produtores - cerca de $70 \%$ do café produzido no mundo é cultivado por produtores com menos de 10 hectares (OXFAM, 2002) -, até grandes tradings e empresas torrefadoras, que constituem respectivamente verdadeiros oligopsônios na compra do grão verde e oligopólios na venda do café torrado e moído, passando por associações e cooperativas de produtores, pequenos atravessadores (corretores) e especuladores financeiros.

Por se tratar de uma commodity tropical (TOPIK, 2003), isto é, um produto agropecuário produzido pelos países tropicais e consumido quase que exclusivamente pelos países desenvolvidos, o circuito espacial produtivo do café caracterizase historicamente por fortes relações desiguais de poder. Estas se intensificaram a partir da década de 1990, com a retração do poder de regulação estatal e o consequente aumento da atuação corporativa, num contexto de mundialização da ideologia e das políticas neoliberais (PECK; TICKEL, 2002;
HARVEY, 2004). Dentre os principais eventos daquele período, relacionados ao mercado cafeeiro, destacam-se: o fim dos Acordos Internacionais do Café (AICs), estabelecidos entre os Estados produtores e consumidores para a regulação dos preços e dos volumes comercializados por cada país, vigentes entre 1962 e 1989; e a extinção de diversos institutos estatais responsáveis pela política cafeeira, como o caso do Instituto Brasileiro do Café, em 1990. A chamada "desregulamentação do mercado cafeeiro" (SAES, 2007) tratou-se na verdade do fortalecimento da "regulação corporativa" exercida, sobretudo, pelas tradings agrícolas, pelas empresas de torrefação e moagem e varejistas.

O fim da fase de forte regulação estatal deu origem a um período denominado de "crise do café", devido à queda acentuada do preço do café verde no mercado internacional, que alcançou os menores índices históricos no início das décadas de 1990 e 2000, e também pela redução do percentual da renda total apropriada pelos países produtores de cerca de $50 \%$, na década de 1970 , para meros $13 \%$ em 2000 (DAVIRON; PONTE, 2007). Atualmente, os produtores recebem menos de $10 \%$ do preço final do café ao consumidor, ante a média de $25 \%$ na década de 1970 (TALBOT, 2004). Como demonstram Daviron e Ponte (2007), a redução dos valores pagos aos cafeicultores foi acompanhada paradoxalmente pelo aumento significativo do volume de café comercializado mundialmente e do valor auferido pelas grandes empresas nas etapas finais do circuito. Desde o início da década de 2000, houve um crescimento de quase $35 \%$ da demanda mundial de café (o consumo mundial aumentou de cerca de 100 para aproximadamente 145 milhões de sacas de 60 $\mathrm{kg}$ entre 2000 e 2014) e também a multiplicação das formas de consumo do produto (espresso, capuccino, monodoses e preparações geladas), com a popularização de novos tipos de cafeteria, cujos modelos criados pela Starbucks e Nespresso (Nestlé) estão entre os melhores exemplos.

A produção dos denominados "cafés especiais" surgiu como uma resposta dos produtores, associações e ativistas à regulação corporativa e à queda dos preços internacionais supracitados. Segundo Bacon (2008), a produção de cafés 
especiais foi estimulada pelo interesse de algumas empresas e consumidores vinculados ao discurso da sustentabilidade ambiental e por grupos insatisfeitos com as condições precárias de reprodução dos pequenos cafeicultores nos países produtores.

Não há consenso sobre a definição de "cafés especiais". Numa concepção mais restrita, a Specialty Coffee Association of America (SCAA) considera apenas aqueles que apresentam elevada qualidade física e sensorial, alcançando acima de 80 pontos, numa escala de 0 a 100. Entretanto, adotamos a definição proposta pela Associação Brasileira de Cafés Especiais (Brazil Specialty Coffee Association - BSCA), que além da qualidade da bebida, também considera critérios ambientais e sociais de produção (condições de trabalho, preservação ambiental, formas de organização dos produtores, entre outros). Dessa forma, cafés especiais são todos aqueles que apresentam algum tipo de diferencial, seja qualitativo, seja atrelado a aspectos sociais ou ambientais, como: Gourmet, Orgânico, Comércio Justo e com Indicação Geográfica.

Como ressaltado no início do texto, em 2012, esse segmento representava $12 \%$ do mercado mundial, com consumo localizado principalmente nos países desenvolvidos, com ágio médio no preço final entre 30 a $40 \%$, quando comparado ao café convencional (BSCA, 2013). Autores, como Pereira et. al. (2011) e Souza, Saes e Otani (2002), demonstram que desde a década de 1990, houve um significativo aumento da produção de cafés especiais no Brasil. Estima-se que $8 \%$ da safra brasileira de 2012 foi comercializada como café especial, com exportação de $75 \%$ desse total, principalmente, para os Estados Unidos, Japão e Europa (BSCA, 2013).

Todavia, com o aumento mundial desse nicho de mercado, grandes empresas torrefadoras (Kraft/Philip Morris, Nestlé, Sara Lee, J.M. Smucker's, Elite), tradings (Neumann, Ecom, Olam, ED\&F Man, Louis Dreyfus) e varejistas (Starbucks, McDonalds) também têm sido atraídas para o circuito de cafés especiais. A inserção no Comércio Justo, por exemplo, permite agregar valor aos seus produtos e melhorar sua "imagem empresarial", vinculando-a a questões relacionadas à "responsabilidade social e ambiental". Além da renda auferida pela comercialização de produtos com maior valor de mercado, as empresas se apropriam também de rendas de monopólio (PAULANI, 2012), ao valorizar suas marcas por meio do marketing empresarial. Para Paulani (2012), no capitalismo contemporâneo, a renda de monopólio não resulta apenas da qualidade singular de um produto que possui condições naturais excepcionais de produção, ela agora pode ser produzida artificialmente pela valorização da "marca". Além de ajudar a vender a mercadoria, a marca gera valor, pois os consumidores "pagam o que for necessário" para adquiri-la, o que assegura uma renda de monopólio.

Como consequência, autores como Daviron e Vagneron (2011) falam de uma possível recommoditização dos cafés especiais. Para os autores, o comércio mundial de commodities agrícolas caracteriza-se principalmente pela "padronização" dos produtos e dos preços, estabelecidos em bolsas de valores. Porém, como destacado anteriormente, a emergência de movimentos sociais nos países desenvolvidos entre as décadas de 1960 e 70, fizeram surgir circuitos de produção de cafés que se comportavam como uma espécie de anticommodity, isto é, visavam fortalecer a relação entre produtor e consumidor final, a partir da maior transparência do sistema produtivo (fim do anonimato do produtor) e do estabelecimento de um preço justo, acima dos custos de produção e suficiente para a reprodução dos pequenos cafeicultores. De certa forma, a proximidade entre produtores e consumidores conferia maior "autonomia" e "identidade" às negociações (DAVIRON; PONTE, 2007), assegurando a diminuição no número de intermediários e o aumento da participação dos cafeicultores na renda final dos produtos.

Todavia, a partir da década de 1990, houve certa "repadronização" das características e dos preços dos cafés especiais, com o intuito de ampliar a sua comercialização, o que restaurou a distância na relação entre os produtores e o consumidor final. Os autores consideram essa nova padronização imposta ao comércio de cafés especiais como uma recommoditização da produção.

Outra importante questão relacionada à padronização e perda de autonomia dos produtores 
refere-se às formas de atuação das empresas certificadoras. Elas foram criadas como uma maneira de assegurar a credibilidade do produto junto aos consumidores, devido à grande expansão das redes de produção e consumo (SOUZA, 2006). Porém, se por um lado, a certificação possibilita aos produtores a inserção em determinados nichos de mercado. Por outro lado, exclui aqueles que não podem pagar pelo serviço ou não atendem às exigências das certificadoras, ao mesmo tempo em que repadroniza os produtos e formas de produção.

Destarte, ainda que os cafés especiais estejam cada vez mais inseridos numa lógica comercial similar à das demais commodities agrícolas, em alguns casos, como em certas regiões brasileiras, a sua produção tem acarretado benefícios importantes para determinados grupos de produtores. Ainda que polêmica, a produção de alguns tipos de cafés especiais, como o Comércio Justo, além de assegurar uma renda maior, tem gerado outros benefícios, como a organização coletiva dos produtores e melhores práticas de manejo e condução da propriedade agrícola, como verificado na última parte deste artigo.

\section{GLOBALIZAÇÃO DO COMÉRCIO JUSTO E CAFEICULTURA}

As primeiras iniciativas do movimento atualmente denominado Fair Trade (Comércio Justo) surgiram de ações descentralizadas de grupos voluntários (filantrópicos e religiosos) que realizavam projetos sociais em países subdesenvolvidos entre as décadas de 1960 e 70 (TALLONTIRE, 2000). Esses grupos forneciam ajuda financeira e organizacional aos pequenos produtores familiares, com o intuito de criar mercados alternativos, a partir de relações mais próximas entre produtores do Sul e consumidores do Norte (JAFFEE, 2012).

Inicialmente, os produtores eram reconhecidos pela autodeclaração e reputação, com o estabelecimento de relações comerciais informais, feitas em bazares e feiras nos países desenvolvidos (SCHNEIDER, 2007). Para os ativistas do Comércio Justo, as trocas comerciais deveriam ser "justas", isto é, os preços pagos pelos produtos deveriam cobrir os custos de produção e proporcionar uma margem de renda digna para a reprodução dos pequenos produtores.

A partir da década de 1970, as ações descentralizadas do Comércio Justo começaram a se organizar nas denominadas Organizações de Comércio Alternativo (ATO - Alternative Trade Organizations). As ATO's visavam combater a pobreza por meio do comércio, como as pioneiras: Traidcraft, Oxfam, Solidaridad, Equal Exchange e Artisans du Monde. Essas entidades compravam os produtos diretamente de organizações de produtores de países subdesenvolvidos e os vendiam em suas lojas de varejo na Europa e EUA, conhecidas como Lojas do Mundo (World Shops). Segundo Daviron e Ponte (2007), as Lojas do Mundo se esforçavam em gerar "autoconhecimento" entre os agentes participantes do Comércio Justo, por meio da transmissão de informações e da organização de visitas entre representantes dos produtores e consumidores.

Todavia, nas décadas de 1980 e 1990, as ações filantrópicas começaram a se formalizar. A ênfase deixou de ser centrada apenas nos produtores e passou a incorporar também as demandas dos consumidores (TALLONTIRE, 2000). As exigências por maior segurança alimentar e padrões de qualidade e a concorrência com outras redes varejistas fizeram com que as Lojas do Mundo adotassem uma estrutura administrativa e comercial mais formal e burocratizada (DAVIRON; PONTE, 2007).

Para isso, foi criada, em 1997, a Fairtrade Labelling Organization International (FLO), uma rede internacional que unificou as organizações nacionais e os demais agentes envolvidos no Comércio Justo (produtores, exportadores, organizações de consumidores, entre outros). O principal objetivo da FLO é coordenar e regular o sistema internacional do Comércio Justo, desde a produção até o consumo final. Dentre as principais medidas adotadas pela nova organização destaca-se a substituição do modelo filantrópico e de compra direta, defendido inicialmente pelas ATO's, pela obrigatoriedade da certificação como forma de garantia aos consumidores da origem e da qualidade dos produtos Fairtrade.

A auditoria de certificação das associações, realizada pela FLO Certification of Social-Economic 
Development GmbH (FLO-Cert), avalia a estrutura organizacional e os critérios sociais, econômicos e ambientais envolvidos na produção e comercialização dos produtos. Os critérios se dividem em iniciais (para a obtenção da certificação), de progresso (de acordo com o número de anos de permanência no Comércio Justo), gerais (obrigatórios para qualquer tipo de produção) e específicos por produto. São cobradas diversas taxas para inserção e permanência no sistema FLO, de acordo com o tipo e o número de pessoas associadas às organizações. Para comercializar produtos do Comércio Justo, empresas exportadoras, armazéns e redes varejistas também devem ser certificados, porém os critérios são menos exigentes, de maneira geral se requer maior "transparência" e "diálogo" nas negociações com os produtores.

Com a sua formalização, o circuito produtivo do Comércio Justo se mundializou. No ano de 2012, existiam 1.149 organizações certificadas distribuídas em 70 países. Desse total, 595 se encontravam na América Latina e Caribe, 393 na África e 161 na Ásia e Pacífico. Essas organizações reuniam mais de 1,2 milhão de trabalhadores e produtores localizados principalmente na África e Oriente Médio (59\% do total) e América Latina e Caribe (24\%) (FLO, 2012).

O café, por sua característica de commodity tropical, produzida em sua maioria por pequenos produtores, e com grande demanda pelos países desenvolvidos, tornou-se o principal produto do Comércio Justo. No ano de 2011, do total de 1,3 milhão de hectares cultivados com produtos do Comércio Justo, cerca de $60 \%$ eram de café, com 348 organizações e mais de 580 mil pequenos agricultores, em 28 países (FLO, 2012) (Figura 1).

Figura 1 - Número de Organizações do Comércio Justo por País, 2011

Café Fairtrade: organizações de produtores com café certificado - 2011

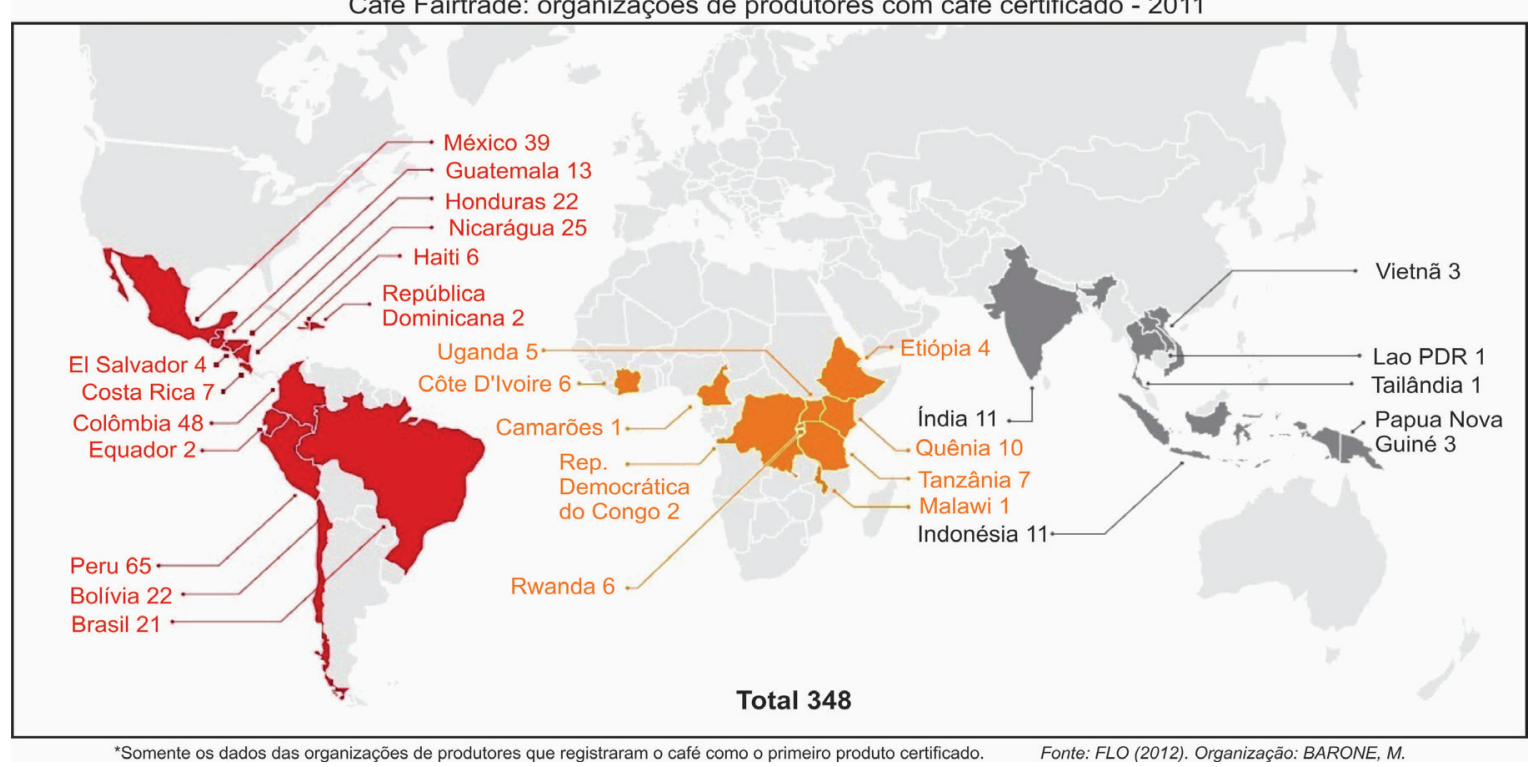

Fonte: Adaptado de FLO (2012).

Do total de cafeicultores certificados, cerca de 340 mil (59\%) localizavam-se na África, aproximadamente 190 mil $(32,2 \%)$ na América Latina e Caribe e quase 50 mil (8,7\%) na Ásia e Oceania, com tamanho médio das propriedades de apenas 1,4 hectare. Com relação ao consumo, como ressaltado anteriormente, a maior parte se realiza nos países desenvolvidos. Em 2012, dos 4,8 bilhões de euros gastos com produtos do Comércio Justo em todo o mundo, o Reino Unido foi responsável por 
aproximadamente $40 \%$ dos dispêndios totais, seguido pela Alemanha, França, Suíça e Canadá (FLO, 2012).

Contudo, a mundialização do Comércio Justo e a criação de padrões internacionais de certificação suscitaram diversas controvérsias. Para a FLO (2009), o Comércio Justo mantém seus princípios originários, ao promover uma maior igualdade no comércio internacional, oferecer melhores condições comerciais e assegurar os direitos dos pequenos produtores e trabalhadores marginalizados. Porém, autores como Daviron e Vagneron (2010) argumentam que a certificação restaurou a distância na relação comercial entre produtores e consumidores, promovendo de certa forma sua recommoditização.

Apesar de controverso, observações realizadas em trabalhos de campo no Brasil (Poços de Caldas e Boa Esperança, Minas Gerais) e no exterior (San José, Heredia, Llano Bonito e San Miguel, na Costa Rica), revelaram que o Comércio Justo representa diferentes benefícios de acordo com as características intrínsecas de cada formação socioespacial (SANTOS, 1977). Em países como a Costa Rica, com forte tradição na organização dos pequenos produtores e na produção de cafés especiais, a certificação do Comércio Justo tornou-se apenas mais uma entre diversas outras (Rainforest, UTZ, 4C, etc.), isto é, deixou de ser um fator de exclusividade, para se tornar obrigatória, como forma de inserção dos produtos no mercado mundial. $\mathrm{Na}$ verdade, o que se verifica é uma postura crítica mais veemente por parte dos produtores, que reivindicam maior independência com relação às certificações, elevação do preço mínimo e maior poder decisório no conselho diretivo da FLO. Existem diversas iniciativas para que os próprios produtores sejam responsáveis por certificar e garantir os atributos socioambientais de seu café e também para a criação de canais diretos de comercialização com cafeterias, em particular, nos EUA.

Todavia, em países como o Brasil, reconhecido pela produção de grandes quantidades de café convencional e com menor tradição relativa de organização dos pequenos cafeicultores, a prática do Comércio Justo tem proporcionado, pelo menos num primeiro momento, importantes benefícios para algumas associações de produtores. No território brasileiro, as primeiras iniciativas do Comércio Justo vinculadas à FLO ocorreram somente no final da década de 1990, decorrentes, sobretudo, dos problemas enfrentados pela cafeicultura naquele momento. Uma das primeiras cooperativas a realizar vendas de café via Comércio Justo foi a Cooperativa dos Agricultores Familiares de Poço Fundo (COOPFAM), em 1997. Desde então, o movimento se expandiu e incorporou outros produtos como frutas, mel, algodão e castanha de caju. Em 2013, existiam 67 organizações de produtores e empresas certificadas pela FLO no país. Desse total, 28 eram organizações de cafeicultores, localizadas principalmente nos estados de Minas Gerais (16), Espírito Santo (5) e São Paulo (4). No intuito de contribuir para o debate sobre os benefícios e as formas de inserção de pequenos cafeicultores brasileiros no circuito produtivo do Comércio Justo, o próximo item aborda a situação da Associação dos Agricultores Familiares do Córrego D’Antas Assodantas.

\section{ASSODANTAS E O COMÉRCIO JUSTO}

A Associação dos Agricultores Familiares do Córrego D'Antas localiza-se no município de Poços de Caldas, no sul de Minas Gerais, onde foram realizadas pesquisas de campo (em junho de 2013). Trata-se de uma tradicional região produtora de café, cuja atividade surgiu com a expansão da ferrovia Mogiana, no final do século XIX. Além da tradição, a região possui também condições edafoclimáticas favoráveis à produção de cafés de qualidade superior, com altitude média de $1.200 \mathrm{~m}$, temperaturas amenas durante o ano, entre 18 e $24^{\circ} \mathrm{C}$, e chuvas concentradas no período da florada e desenvolvimento dos grãos, seguida por uma estação seca na época da colheita.

A Associação foi criada em 2004, como uma alternativa dos pequenos produtores à já citada crise internacional do café das décadas de 1990 e 2000. Atualmente, ela conta com 65 membros, incluindo alguns cafeicultores do município vizinho de Caconde (SP), com propriedades que variam de 5 a 12 hectares.

A certificação do Comércio Justo foi obtida em 2009, por meio do incentivo da prefeitura de Poços de Caldas e do Sebrae-MG. Os custos iniciais 
de certificação, no valor de cerca de R \$ 6 mil, foram pagos com dinheiro arrecadado pela realização de festas populares na própria comunidade. A primeira venda de café certificado ocorreu em 2010, com a exportação de 20 contêineres. Na safra 2012/2013, os associados possuíam 517 hectares plantados de café, com produção de 8.531 sacas. Deste total, cerca de $60 \%$ atingiu a qualidade exigida para ser exportada pelo Comércio Justo (denominada popularmente de "café xícara limpa").

Conforme o café é colhido manualmente, entre os meses de maio e setembro, os associados levam uma amostra até o escritório da Associação, onde é feita uma triagem (as amostras são enviadas aos compradores para avaliação). Diversos produtores contratam trabalhadores para a colheita, entretanto, há predominância do uso da própria mão de obra familiar. O contato com os compradores é feito geralmente em visitas dos representantes da Assodantas em feiras organizadas por instituições de fomento à cafeicultura, tal como a Specialty Coffee Association of America, nos EUA. Além disso, a FLO envia para a Associação uma lista de todos os compradores certificados pelo Comércio Justo.

Depois de colhido e beneficiado nas dependências da própria Associação, o café é armazenado em barracão alugado até o final da comercialização. Em seguida, ele é levado para a Internacional Armazém Gerais (empresa especializada na armazenagem de cafés especiais localizada no próprio município de Poços de Caldas) para ser rebeneficiado (classificação e últimos preparos para alocação dos lotes nos contêineres) e despachado. Todo o sistema de transporte (das fazendas até o porto de Santos) é realizado por rodovias, em caminhões alugados.

A empresa Bourbon Specialty Coffee (BSC), também localizada em Poços de Caldas (MG), e pertencente à trading Ecom - uma das maiores tradings internacionais de café -, é a responsável pela exportação do café da Assodantas. Na última safra, os principais destinos foram Suíça, EUA, Reino Unido e Japão. Uma pequena parte do café Fairtrade é vendida para a torrefadora Spress Café, localizada no mesmo município, pioneira na comercialização desse tipo de café em um país produtor. Os grãos que não alcançam a qualidade para serem vendidos pelo Comércio Justo deixam de ser de responsabilidade da Assodantas e são comercializados individualmente pelos produtores.

O preço da saca do café varia de acordo com a cotação da Bolsa de NY, da sua catação (eliminação dos principais defeitos e resíduos) e qualidade. Em média, o café da Assodantas vendido pelo Comércio Justo alcança valores entre $20 \%$ e $30 \%$ acima do convencional. Além do preço adicional, a Associação recebe também um valor Premium que deve ser utilizado em projetos coletivos. Na safra 2012/2013, a Assodantas arrecadou cerca de R\$ 200 mil em Premium do Comércio Justo. O dinheiro foi utilizado para a instalação do atual escritório, para a construção de fossas sépticas na comunidade rural e para a compra do terreno onde será construído o armazém da Associação. Além disso, esse dinheiro também é utilizado para o pagamento de dispêndios diversos como: beneficiamento/rebeneficiamento e transporte do café, compra de sacarias, participação em feiras nacionais e internacionais, manutenção anual da certificação e oferta de crédito aos associados.

Apesar das contradições referentes à subordinação do Comércio Justo à lógicainternacional do mercado de commodities, como ressaltado nos itens anteriores, pode-se considerar que a inserção da Assodantas nessa forma de comércio promoveu importantes alterações na organização e atuação dos produtores. Antes da criação da Associação e da inserção no CJ, os produtores vendiam seu café diretamente para os corretores locais, sem nenhum tipo de classificação, e a preços inferiores aos do café convencional cotado em bolsa. Após ser adquirido, o café era selecionado e vendido para corretores maiores que só então os revendiam para as empresas exportadoras. Ou seja, entre os produtores e as empresas exportadoras, o café passava por no mínimo dois intermediários (corretor local, empresas corretoras, etc.). Além da falta de transparência nas negociações, os produtores não classificavam o café colhido - com a retirada de defeitos e impurezas e separando-o de acordo com o tipo de grão -, e desconheciam completamente o destino de seus cafés.

Com a inserção no CJ, o café passou a ser 
vendido diretamente para a empresa exportadora, eliminando os intermediários locais. Apesar da BSC pertencer a Ecom, isto é, dos produtores continuarem subordinados à uma grande corporação inserida na lógica do comércio mundial de commodities, eles obtiveram diversas vantagens: diminuição no número de intermediários até o consumidor final; pagamento do Premium; maior visibilidade da Associação e interesse dos produtores em se associar; aumento do preço pago pelos cafés, acima do convencional; e maior informação sobre os compradores e o destino dos grãos.

De maneira geral, o atual presidente da Assodantas considera que com o CJ foi criada uma relação mais próxima entre os diferentes agentes do circuito produtivo (produtor/associação, exportador, torrefador e importador). Ele afirma que "antes da certificação, o caminhão [corretor] vinha até as nossas fazendas, pegava o café e ia embora, nós não sabíamos para onde o café era levado". Com a inserção no Comércio Justo, além de conhecer o destino dos seus cafés, frequentemente os compradores visitam ou estão em contato com os produtores.

De maneira geral, as exigências feitas pelo CJ estimularam também a organização coletiva dos produtores e o desenvolvimento de melhores práticas de manejo na propriedade agrícola. No primeiro caso, ressalta-se a necessidade do cumprimento dos critérios de organização da Associação, como a realização de assembleias e a oficialização das tomadas de decisão. Com relação à organização das propriedades, destacam-se: a) a adoção de novas práticas de manejo, tais como a proibição do uso de agrotóxicos não permitidos pela FLO, a substituição do uso de herbicidas pela roça do mato e o combate à erosão do solo; b) as novas práticas de armazenamento e classificação para manutenção da qualidade e dos padrões de exportação; c) a divisão dos cafeeiros em talhões e maior preocupação com a rastreabilidade do produto; d) o conhecimento mais sistemático sobre a evolução da produtividade e dos custos de produção.

Porém, a organização coletiva e a melhoria das práticas de manejo não se alcançam repentinamente. Segundo informações do presidente da Assodantas, a maior dificuldade enfrentada para manter a certificação do Comércio Justo é convencer os produtores a participarem das assembleias e das tomadas de decisões da Associação. A histórica falta de organização coletiva dos pequenos cafeicultores se expressa, por exemplo, na venda de cafés que poderiam ser comercializados pelo $\mathrm{CJ}$ para corretores locais. Nos momentos de alta dos preços internacionais do café, o ágio obtido pela venda via Comércio Justo se comprime, fazendo com que muitos produtores entreguem sua produção no mercado convencional. A recorrência deste tipo de situação acaba por enfraquecer a Associação, sobretudo, diante dos compradores internacionais, pois diminui a credibilidade de oferta regular do café Fair Trade.

\section{CONSIDERAÇÕES FINAIS}

Como demonstrado anteriormente, o Comércio Justo apresentou grande expansão nas últimas décadas, o que acentuou suas contradições e impôs novos desafios. O CJ começou como uma "forma alternativa" de comercialização, que procurava mitigar as desvantagens econômicas e sociais resultantes da lógica do mercado internacional, usando como ferramenta o próprio comércio. Desde a década de 1990, muitas empresas, principalmente nos países desenvolvidos, começaram a adquirir produtos do Comércio Justo, como uma forma de atender à pressão de ativistas e melhorar a sua imagem diante dos consumidores. Com isso, iniciouse uma nova fase do Comércio Justo, marcada por contradições e desafios que giram em torno do interesse da FLO em expandir o sistema sem romper com os seus princípios originais. Como defendem diversos autores (URIARTE, 2002; DAVIRON; VAGNERON, 2010), o Movimento perdeu de certa forma seu caráter "alternativo", com a atual inserção dos produtos Fair Trade nas grandes redes varejistas.

Todavia, entendemos que o Comércio Justo coordenado pela FLO ainda proporciona relativa descommoditização da produção de café, pois se configura como um nicho de mercado, em que parte dos consumidores entende o que a certificação representa e considera o consumo daquele produto como um ato político de apoio aos pequenos 
produtores. Entretanto, também concordamos com Daviron e Vagneron (2010), quando ressaltam a possibilidade de commoditização do Comércio Justo, com a transformação dos produtos Fair Trade em apenas uma marca ou uma exigência de mercado, sem a qual ele não é consumido.

A certificação é um ponto polêmico no escopo de discussão sobre o Comércio Justo, principalmente no que se refere aos custos, procedimentos burocratizados e critérios universais que não levam em consideração a realidade local dos produtores. Além disso, em um mercado tão competitivo e com constantes cobranças socioambientais, o que impede que a certificação, ao se generalizar, não se torne um padrão, um requisito obrigatório para os pequenos produtores, ao invés de um fator de diferenciação? Tal questionamento decorre da observação do número crescente de certificações socioambientais disponíveis no mercado, como: Certificação Orgânica, 4C, Rainforest Aliance, Utz Kapeh, Starbucks C.A.F.E Practices, Nespresso AAA, Bird Friendly e Certifica Minas Café.

Outras importantes questões também resultam das contradições do CJ ser um produto do mercado globalizado, como: ser uma opção de consumo restrita a uma população urbana de alta renda dos países desenvolvidos, que consomem os produtos muito mais como uma característica de seu estilo de vida, um "modismo", do que devido às preocupações de ordem social e ambiental; dos preços oscilarem de acordo com o preço do café convencional cotado na Bolsa de Nova York; e do falso comprometimento das grandes empresas demandantes de café do Comércio justo, que se inserem neste mercado com o intuito principal de criar uma imagem positiva diante da opinião pública (TALBOT, 2004).

Não faz parte do escopo deste artigo, nem é de nossa competência, o aprofundamento dessas importantes questões. Porém, pode-se afirmar, a partir da análise da inserção de algumas associações brasileiras, como a situação da Assodantas, que o Comércio Justo tem sido parcialmente bem sucedido em promover benefícios a partir do uso do Premium, da organização coletiva e produtiva de pequenos produtores e também do estímulo ao debate de algumas questões éticas relacionadas às relações de mercado.

Durante a pesquisa, nos chamou a atenção, o fato dos cafeicultores denominarem o Comércio Justo de "boia de salvação", ou seja, diante de um período marcado pela especulação, instabilidade de preços e vulnerabilidade social dos pequenos produtores, o Comércio Justo garante a inserção em novos mercados e um preço mínimo. Em resumo, pode-se afirmar que os cafeicultores da Assodantas continuam submetidos à lógica das commodities, com pouco ou nenhum controle sobre os preços e normas internacionais. Todavia, mesmo diante dos desafios e contradições, a sua inserção no sistema Fairtrade tem representado mais do que apenas uma certificação socioambiental, assumiu também um papel mitigador de alguns problemas históricos enfrentados pelos pequenos produtores, como a ausência de transparência nas negociações, o grande número de intermediários, a pouca organização coletiva dos produtores, o número restrito de compradores e a obtenção de preços inferiores ao dos cafés convencionais cotados em bolsa.

\section{AGRADECIMENTOS}

$\mathrm{O}$ artigo resulta de pesquisa realizada com apoio da Fundação de Amparo à Pesquisa do Estado de São Paulo (FAPESP).

\section{REFERÊNCIAS}

BACON, C. M. Confronting the coffee crisis: can Fairtrade, organic, and specialty coffees reduce the vulnerability of small-scale farmers in Northern Nicaragua? In: BACON et al. Confronting the coffee crisis. Fair trade, sustainable livelihoods and ecosystems in Mexico and Central America, 2008. p. 128-155. DOI: $10.1016 /$ j.worlddev.2004.10.002

BSCA - BRAZIL ESPECIALTY COFFEE ASSOCIATION. Cafés especiais são destaque em Minas Gerais. Disponível em: <http://bsca.com.br/ noticia.php?id=170>. Acesso em: 30 set. 2013.

CASTILLO, R.; FREDERICO, S. Circuito espacial produtivo do café e competitividade territorial no 
Brasil. Ciência Geográfica. Bauru, Ano X, Volume X, n. 3, 2004, pp. 236-241.

CONDRAS - CONSELHO MUNICIPAL DO DESENVOLVIMENTO RURAL SUSTENTÁVEL. Plano Municipal de Desenvolvimento Rural Sustentável 2012 - 2014. Poços de Caldas, 2012

DAVIRON, B.; PONTE, S. Le paradoxe du café. Paris: Éditions Quae, 2007.

DAVIRON, B.; VAGNERON, I. From commoditisation to de-commoditisation... and back again. Discussing the role of sustainability standards for agricultural products. CIRAD, UMR MOISA, F-34000 Montpellier, França, 2010. Disponível em: <http:// www.prodinra.inra.fr/prodinra/pinra/data/2011/04/ PROD201169c50051_20110419111853467.pdf>. Acesso em: 20 jan. 2012.

FLO - Fairtrade Intenacional. Monitoring the scope and benefits of Fairtrade - Fourth Edition. 2012. Disponível em: <http://www.fairtrade.net/fileadmin/ user_upload/content $/ 2009 /$ resources/2012-FairtradeMonitoring-Scope-Benefits_web.pdf $>$. Acesso em: 12 nov. 2014.

FLO - Fairtrade Intenacional. Carta dos Princípios Fundamentais. 2009. Disponível em $<$ http://www. fairtrade-advocacy.org/images/stories/FTAO charters_3rd_version_ES_v1.3.pdf $>$. Acesso em: 15 nov. 2012.

FREDERICO, S. Lógica das commodities, finanças e cafeicultura. Boletim Campineiro de Geografia, Campinas, v. 3, n. 1, 2013. p. 97-116.

JAFFEE, D. Weak Coffee: certification and CoOptation in the Fair Trade Movement. Social Problems, vol. 59, n.1, 2012. p.94-116. DOI: http:// dx.doi.org/10.1525/sp.2012.59.1.94 94-116

HARVEY, D. O novo imperialismo. São Paulo: Edições Loyola, 2004.
OXFAM. Coffee commodity: a background study. Oxfam: International Commodity Research - Coffee, 2012.

PAULANI, L. Acumulação e rentismo: resgatando a teoria da renda de Marx para pensar o capitalismo. Paper, Rio de Janeiro, ANPEC, 2012.

PECK, J; TICKEL, A. Neoliberalizing space. In: BRENNER, N.; THEODORE, N. Spaces of Neoliberalism: urban restructuring in North America an West Europe. Malden, USA: Blackwell Publishing, 2002. p. 33-57. DOI: 10.1111/1467-8330.00247

PEREIRA, S.P.; AGUIAR, C. M. G.; PRADO, A. S.; GOMES, C. A.; DIAS, R. A. A. Certificação de propriedades cafeeiras. In: TOMAZ, M. A. Tecnologias para a sustentabilidade da cafeicultura. Alegre - ES: CAUFES, 2011.

SANTOS, M. Sociedade e espaço: a formação social como categoria e como método. Boletim Paulista de Geografia, São Paulo, n. 54. 1977. p. 81-100.

SANTOS, M. Circuitos espaciais da produção: um comentário. In: SOUZA, M. A. A.; SANTOS, M. (orgs.). A construção do espaço. São Paulo: Nobel, 1986. p. 121-134.

SCHNEIDER, J. W. Pesquisa Mundial de Comércio Justo: Parte 1, atualização 2010. Brasília: SEBRAE, 2012.

SOUZA, M. C. M. Cafés sustentáveis e denominação de origem: a certificação de qualidade na diferenciação de cafés orgânicos, sombreados e solidários. (Tese de Doutorado) Universidade de São Paulo. São Paulo, 2006.

SOUZA, M. C. M., SAES; M. S. M.; OTANI, M. N. Pequenos produtores familiares e sua inserção no mercado de cafés especiais: uma abordagem preliminar. Informações Econômicas. Instituto de Economia Agrícola, São Paulo, v. 32, n.11, 2002. p. $16-26$. 
TALBOT, J. M. Grounds for agreement: The political economy of the coffee commodity chain. Lanham, MD: Rowman and Littlefield Publishers, INC. 2004.

TALLONTIRE, A. Partnerships in fair trade: reflections from a case study of Cafedirect. Development in Practice. Oxford, vol. 10, n.2, 2000, p. 166-177. DOI: $10.1080 / 09614520050010205$

TOPIK, S. The integration of the World Coffee Market. In: TOPIK, S.; CLARENCE-SMITH, W. G. The global coffee economy in Africa, Asia, and Latin America, 1500-1989.New York: Cambridge University Press, 2003. p. 21-49.

URIARTE, A. Fair Trade: uma introdução e algumas reflexões. Business Meet Social Development, abril de 2002. Disponível em: <http://www.bsd-net.com/ docs/artigoft.pdf.>. Acesso em: 07 de junho de 2014. 